\title{
Microfluidic Tools for Biological Sample Preparation
}

S.R. Visuri, K. Ness, J. Dzenitis, B. Benett, K. Bettencourt, J. Hamilton, K. Fisher, P. Krulevitch

This article was submitted to $2^{\text {nd }}$ Annual International Institute of Electrical and Electronics Engineers-Engineering in Medicine and Biology Society Special Topic Conference on Microtechnologies \& Biology, Madison, Wisconsin, May 2-4, 2002

April 10, 2002 


\section{DISCLAIMER}

This document was prepared as an account of work sponsored by an agency of the United States Government. Neither the United States Government nor the University of California nor any of their employees, makes any warranty, express or implied, or assumes any legal liability or responsibility for the accuracy, completeness, or usefulness of any information, apparatus, product, or process disclosed, or represents that its use would not infringe privately owned rights. Reference herein to any. specific commercial product, process, or service by trade name, trademark, manufacturer, or otherwise, does not necessarily constitute or imply its endorsement, recommendation, or favoring by the United States Government or the University of California. The views and opinions of authors expressed herein do not necessarily state or reflect those of the United States Government or the University of California, and shall not be used for advertising or product endorsement purposes.

This is a preprint of a paper intended for publication in a journal or proceedings. Since changes may be made before publication, this preprint is made available with the understanding that it will not be cited or reproduced without the permission of the author.

This report has been reproduced directly from the best available copy.

Available electronically at http://www.doe.gov/bridge

Available for a processing fee to U.S. Department of Energy

and its contractors in paper from

U.S. Department of Energy

Office of Scientific and Technical Information

P.O. Box 62

Oak Ridge, TN 37831-0062

Telephone: (865) 576-8401

Facsimile: (865) 576-5728

E-mail: reports@adonis.osti.gov

Available for the sale to the public from

U.S. Department of Commerce

National Technical Information Service

5285 Port Royal Road

Springfield, VA 22161

Telephone: (800) 553-6847

Facsimile: (703) 605-6900

E-mail: orders@ntis.fedworld.gov

Online ordering: http://www.ntis.gov/ordering.htm

\section{OR}

Lawrence Livermore National Laboratory

Technical Information Department's Digital Library

http://www.llnl.gov/tid/Library.html 


\title{
MICROFLUIDIC TOOLS FOR BIOLOGICAL SAMPLE PREPARATION
}

\author{
Steven R. Visuri, Kevin Ness, John Dzenitis, Bill Benett, Kerry Bettencourt, \\ Julie Hamilton, Karl Fisher, Peter Krulevitch. \\ Lawrence Livermore National Laboratory, Livermore, CA
}

\begin{abstract}
Researchers at Lawrence Livermore National Laboratory are developing means to collect and identify fluid-based biological pathogens in the forms of proteins, viruses, and bacteria. To support detection instruments, we are developing a flexible fluidic sample preparation unit. The overall goal of this Microfluidic Module is to input a fluid sample, containing background particulates and potentially target compounds, and deliver a processed sample for detection. We are developing techniques for sample purification, mixing, and filtration that would be useful to many applications including immunologic and nucleic acid assays. Sample preparation functions are accomplished with acoustic radiation pressure, dielectrophoresis, and solid phase extraction. We are integrating these technologies into packaged systems with pumps and valves to control fluid flow and investigating small-scale detection methods.
\end{abstract}

Keywords - microfluidic, dielectrophoresis, acoustic, sample preparation, nucleic acid, immnuoassay

\section{INTRODUCTION}

At Lawrence Livermore National Laboratory (LLNL) we are developing instruments for the detection of biological agents with applications in clinical medicine and national security. These instruments make use of nucleic acid-and immuno- assay techniques for the detection of viruses, bacteria, and proteins. Instruments are designed to operate autonomously - continuously sampling the environment and performing assays; or operate on demand at the point-of-care. Samples are typically introduced to downstream sample preparation and detection in a liquid format. Aerosolized particles are captured into a buffer solution and delivered downstream. Human samples are inherently fluids (e.g. mucus, serum, urine). Environmental or clinical samples often contain significant amounts of background contaminants. In order to improve the sensitivity and performance of the assays, sample preparation steps need to be performed prior to assay incubation/hybridization and detection. We are developing sample preparation tools that enable sample purification, concentration, amplification, and multiplex detection. In an effort to miniaturize instruments and reduce reagent volumes, we are looking to perform some or all aspects of sample collection through detection on a microfluidic platform. We have evaluated several technologies and have begun incorporating the most promising into complete instruments. Samples can be filtered or concentrated through the use of acoustic filtration. This concentration technique creates pressure nodes that concentrate and trap particles in a fluid stream. Acoustic energy can also be used to efficiently mix reagents and samples with the advantage of improving assay kinetics. Another technique being explored for sample purification or concentration is Dielectrophoresis (DEP). DEP creates electric field gradients that can selectively trap specific particles through manipulation of the electrical stimulus. We have demonstrated sample purification by selective DEP capture of contaminants in a flowing fluid. Acoustics and DEP have been demonstrated with bacteria and microbeads. DEP has also been shown to capture smaller samples such as DNA. A promising technology for DNA concentration and purification has been a microfluidic adaptation of solid phase extraction. These microfluidic sample processing methods will lead to miniaturized portable devices that decrease reagent requirements and improve assay sensitivity. Finally, we have developed or adopted fabrication techniques for rapidly prototyping and integrating components. These components are being packaged in a polydimethylsiloxane (PDMS) platform for ease of fabrication and utility.

\section{METHODOLOGY}

We have designed an initial architecture for our MicroFluidic Module that assumes fluid-based sample introduction. Sample introduction may range from simple manual pipetting or spotting to more sophisticated automated techniques. We further assume that the introduced samples contain background material that at least complicates performance of the assay and at worst prevents performance of assays. Background materials may raise the level of background signal, interfere with binding of reagents and labels, or inhibit assay performance. Therefore, it is advantageous in many scenarios to purify samples prior to performance of assays and delivery to detection instruments. Also, concentration of target molecules may ease sample handling, conserve reagents, and raise detection sensitivity. To accomplish these goals, we are investigating several technologies including acoustic particle-manipulation, dielectrophoresis, and DNA capture on a silicon chip.

\section{A. Acoustic Devices}

Acoustic radiation was generated from piezoelectric transducers and coupled into flow chambers made of glass 
or acrylic. The acoustic waves were used to manipulate particles suspended in a fluid. The action on the particles depended on the acoustic pattern in the flow field. Radiation pressure generated in a frequency matched chamber can produce standing pressure wave patterns. The pressure gradients cause particles to collect in the nodes or anti-nodes of the standing wave. This coordinated particle movement can be used to concentrate or filter larger particles from a sample. Uncoordinated (not tuned to cavity) generation of acoustic radiation can cause random particle motion, useful for fluid mixing. The acoustic force exerted on a particle can be expressed as,

$$
F_{\mathrm{ac}}=-4 \pi / 3 \mathrm{R}^{3} \mathrm{kEA} \sin (2 \mathrm{kx})
$$

where $R$ denotes the particle radius, $k$ is the wave number, and $E$ is the acoustic energy density [1-5]. The compressidensity factor, A, reflects the relative density and compressibility of the particle with respect to the ambient medium. The sign of $A$ determines whether the particles move to areas of high or low pressure.

\section{Acoustic Mixing}

Mixing is challenging in microfluidics since small channel dimensions make it difficult to create turbulence. Mixing by diffusion is slow, with diffusion rates on the order of one $\mathrm{mm}$ in 20 minutes. Acoustic mixing offers advantages of rapid mixing, no moving parts, and no need for external injection of fluids or nozzles to create turbulence. We have demonstrated increased mixing using acoustic radiation in fluid chambers. Rectangular lead zirconate titanate (PZT) transducers were coupled to glass or plastic flow chambers. Piezoelectric transducers were driven at $15-40 \mathrm{~V}_{\mathrm{pp}}$ and frequencies of 0.1-5 MHz. Concentrations of Bacillus globigii (B.g.) spores bound to antibody coated $5 \mu \mathrm{m}$ spheres were added to the sample chamber. Subsequently a fluorescent labeled antibody was added and acoustic mixing initiated. Following mixing, the sample was analyzed and the amount of fluorescent label attached to the microspheres quantified with a flow cytometer.

\section{Acoustic Concentration}

Acoustic radiation was also used to produce standing pressure waves that concentrated particles in a flow field. Flow rates up to $500 \mu 1 / \mathrm{min}$ were produced by a syringe pump. Transducers were powered at $40 \mathrm{~V}_{\mathrm{pp}}$ and $3.3 \mathrm{MHz}$. Polystyrene particles of $6 \mu \mathrm{m}$ diameter were suspended in a solution of water. A volume of suspended beads was delivered into the chamber. The acoustic transducers were excited, capturing and concentrating particles in the pressure nodes while flow continued. Fluid exiting the chamber was collected. Power to the piezoelectric transducers was then removed and clean water flowed through to remove beads that were previously trapped by the acoustics. The amount of beads retained was quantified by counting the recovered solution on a flow cytometer and comparing to the original concentration. This method is useful for concentration and filtration of samples.

\section{B. Dielectrophoresis}

An alternative method of concentrating particles and retaining them in a flowing stream is the use of dielectrophoresis [6]. Unlike acoustics which function better on larger particle, DEP works across a wide range of particle sizes from small strands of DNA to larger cells and bacteria. The dielectrophoretic force results from the ability of a particle to become polarized in the presence of a non-uniform electric field. Particles in the field will be attracted to areas of high or low field gradient depending on the particles electrical properties relative to those of the suspending medium, and the frequency of excitation. The use of DEP forces becomes practical in microfluidic devices because sufficient field strengths are achievable at sub-millimeter dimensions with only a few volts applied to the electrodes.

A DEP chamber was fabricated to test the ability to separate particles from a flowing suspension. DEP devices consisted of interdigitated $30 \mu \mathrm{m}$-wide platinum electrodes fabricated on glass using standard photolithographic methods. The interdigitated electrodes were $2.2 \mathrm{~cm}$ long, $30 \mu \mathrm{m}$ wide and spaced $30 \mu \mathrm{m}$ apart. An AC voltage of $1-5 \mathrm{~V}_{\mathrm{rms}}$ and $100 \mathrm{~Hz}-1 \mathrm{MHz}$ was applied between the electrodes. Particles were observed under a $100 \times$ microscope to confirm DEP trapping. A sample solution of $3.4 \mu \mathrm{m}$ polystyrene beads was mixed with Arizona Road Dust in an aqueous solution. A volume of this solution was pumped through the DEP chamber with and without the DEP electrodes energized. Samples were collected for subsequent analysis on a flow cytometer. The flow cytometer was configured to measure particles between 0.4 and $15 \mu \mathrm{m}$ and concentrations of $10^{2}$ to $10^{7}$ particles $/ \mathrm{ml}$. Ten volumes of $1 \mu \mathrm{l}$ were counted and averaged for each sample.

\section{DNA Capture Chip}

A microfluidic method of performing solid phase DNA extraction was developed. DNA is known to adsorb to silica and subsequently release under proper buffer $\mathrm{pH}$ conditions. Commercial kits are available to perform this function but they typically require many labor intensive steps including centrifugation. A microfluidic approach has many advantages including control over surface area and flow rate and is amenable to automation. A DNA capture chip was produced by creating thousands of silicon pillars through standard micromachining of silicon wafers. Several shapes (cylindrical, rectangular, etc), distributions, and spacings (typically $5-30 \mu \mathrm{m}$ ) of pillars were produced by standard lithography and deep reactive ion etching techniques. The pillars were oxidized and covered and sealed by bonding a glass slide on top of the chip. Fluidic inputs were fabricated so that samples could 
be introduced into the chip and flowed around the densely packed field of micropillars. Concentration of DNA was demonstrated by passing a quantity of Francisella tularensis (F.t.) genomic DNA through the chip, capturing the DNA out of solution, eluting the DNA into a smaller volume of solution, and quantifying the resulting concentration using real-time PCR. Starting concentration of $10^{2}$ copies $/ \mathrm{ml}$ was well below the detection limit of approximately $10^{4} / \mathrm{ml}$. A total of $75 \mathrm{ml}$ at $10^{2} / \mathrm{ml}$ was processed through the chip and DNA eluted into approximately $5 \mu 1$. The $5 \mu 1$ drop was diluted into $10 \mu 1$ and analyzed using real-time-PCR along with "unprocessed" $10^{2} / \mathrm{ml}$ and $10^{4} / \mathrm{ml}$ samples.

\section{RESULTS}

\section{A. Acoustic Devices}

\section{A.1. Acoustic Mixing}

We have previously demonstrated that increasing the drive voltage on the piezoelectric transducers increased the amplitude of the acoustic waves, and increased the fluid mixing. This was also confirmed with Particle Image Velocimetry. Figure 1 shows the results of increased binding of a fluorescent antibody as mixing of the sample is increased.

\section{A.2. Acoustic Concentration}

We have demonstrated acoustic concentration in flowing fluids using single element rectangular chambers. In this configuration, a standing wave was created by reflecting the acoustic wave off the opposing wall of the chamber. Figure 2 demonstrates the retention efficiency of $6 \mu \mathrm{m}$ diameter polystyrene particles held in pressure nodes under various flow rates. At flow rates of $0.1 \mathrm{ml} / \mathrm{min}$, $87 \%$ of the particles were retained within the system; as rates increased to $0.5 \mathrm{ml} / \mathrm{min}$, the retention dropped to $25 \%$.

\section{B. Dielectrophoresis}

We have used dielectrophoresis (DEP) to capture particles from a flowing stream. We have captured a variety of

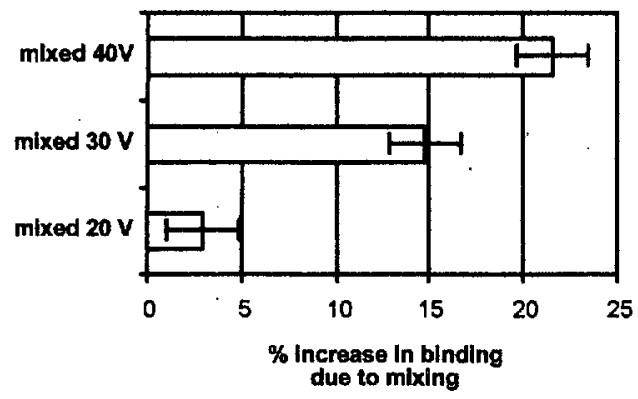

Figure 1. Increase in fluorescent antibody binding to antigen captured on microspheres as mixing is increased $(20$ to $40 \mathrm{~V})$.

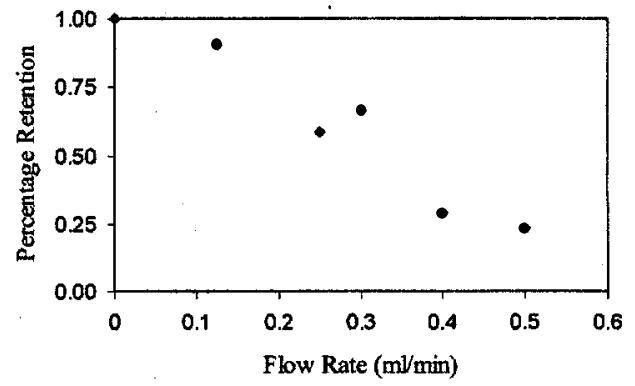

Figure 2. Percentage particle retention vs. flow rate for 6 um diameter beads trapped by acoustic radiation pressure.

particles in homogenous solutions: Bacillus globigii spores, Erwinia herbicola bacteria, DNA, glass beads, and polystyrene beads. Most recently we have begun to collect particles in mixed solutions. We were able to remove a well-characterized background material, Arizona road dust, while allowing a purified solution of polystyrene beads to pass out of the chamber. Particle concentrations, as measured by the flow cytometer at the output of the DEP chamber, are shown in Figure 3. This plots shows a dramatic decrease in dust at the output when the DEP electrodes are active because the dust collects on the electrodes. While maintaining excitation to the electrodes and upon flushing the chamber with water, some additional beads are recovered but virtually no dust. After turning off the DEP electrodes and again flushing with water, the dust releases from the electrodes and flows out of the chamber.

\section{DNA Capture Chip}

The DNA capture chip has proven successful at concentrating relatively pure samples of DNA. By processing large amounts of sample and eluting the captured DNA into a smaller volume, concentrations of approximately 1000x have been obtained (Fig. 4).

Detection of a signal above background for a concentration of $10^{4} / \mathrm{ml}$ occurs after approximately 36 cycles. A concentration of $10^{2} / \mathrm{ml}$ is below our detection limit. By processing $75 \mathrm{ml}$ of $10^{2} / \mathrm{ml}$ solution through the

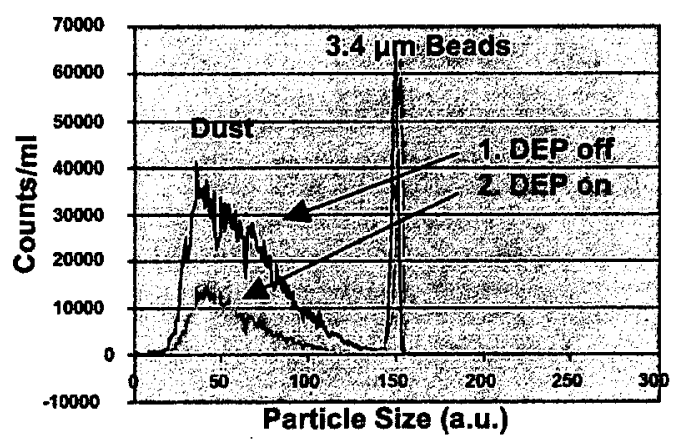

Figure 3. Dielectrophoretic separation of beads and dirt. Dirt can be removed from the flowing fluid by DEP while allowing beads to pass. 


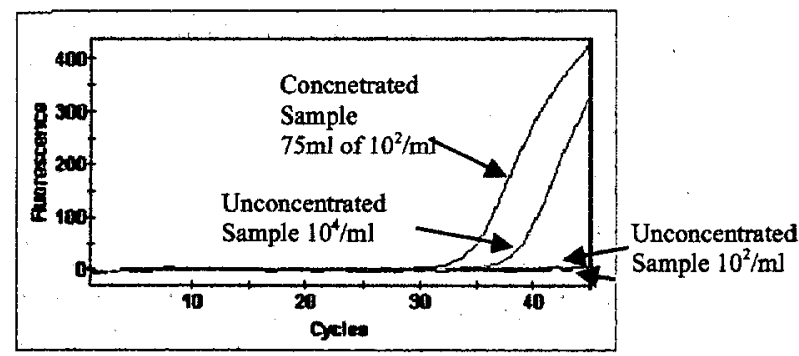

Figure 4. Processing samples through the DNA capture chip yielded approximately $1000 \mathrm{x}$ improvement in concentration.

chip we have been able to detect DNA approximately 3 cycles earlier than a concentration of $10^{4} / \mathrm{ml}$, leading us to believe we have concentrated our sample to approximately $10^{5}$ copies $/ \mathrm{m} 1$, or a $1000 x$ improvement.

\section{DISCUSSION}

We are continuing to evaluate and develop several technologies for biological sample preparation. As these methods prove useful for sample concentration and purification, we are beginning to integrate devices into a flow-through chip format. These methods will enable smaller instruments, require less reagents, and improve detection sensitivities. We are also investigating integration of these sample handling tools with miniature detection and pumping technologies.

\section{ACKNOWLEDGMENT}

This work was performed under the auspices of the U.S. Department of Energy by the University of California, Lawrence Livermore National Laboratory under Contract No. W-7405-Eng-48.

\section{REFERENCES}

1. L. V. King, Proc. Roy. Soc., A, 147. 212, 1934.

2. K. Yosioka, Y. Kawasima, "Acoustic Radiation Pressure on a compressible sphere," Acustica, 5, 167-173, 1955.

3. K. Yasuda, K Takeda, S. Umemura, "Studies on particle separation by acoustic radiation force and electrostatic force, "Jpn. J. Appl. Phys., 35, 3295-3299, 1996.

4. Whitworth, M. A. Grundy, W. T. Coakley, "Transport and harvesting of suspended particles using modulated ultrasound," Ultrasonics, 29, 439-444, 1991.

5. A. H. Meng, A. W. Wang; R. M. White, "Ultrasonic Sample concentration for Microfluidic Systems," Proc. Tenth International Conference on Solid-State Sensors and Actuators, Sendai, Japan, June 1999.

6. X-B Wang, Y. Huang, F.F. Becker, P.R. Gascoyne. J. Phys. D: Appl. Phys. 27 (1994) 1571-1574.

7. Pohl, H.A., 1978, Dielectrophoresis, Cambridge University Press, New York, N.Y. 